\title{
ORIGINAL
}

ARTICLES

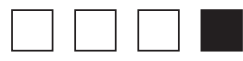

\section{Women's Perspectives on Reproductive Health Services in Primary Care}

Meredith G. Manze, PhD, MPH; Diana R. Romero, PhD, MA; Annie Sumberg, MPH; Monica Gagnon, MPH; Lynn Roberts, PhD; Heidi Jones, PhD, MPH

BACKGROUND AND OBJECTIVES: Primary care providers (PCPs) are increasingly offering reproductive health $(\mathrm{RH})$ services to help address patients' unmet contraceptive needs and improve pregnancy outcomes. We sought to understand patient perspectives on receipt of RH services in primary care settings.

METHODS: We used a purposeful stratified sampling approach to recruit women aged 21 to 40 years into focus groups (FGs) and in-depth interviews (IDIs). We held all four FGs in two New York City neighborhoods and all 18 IDIs in two upstate NY suburban/rural neighborhoods (each with half of the neighborhoods above and below the median county income in each setting type). We explored participants' preferences for RH services from PCPs, including their feelings about being asked about pregnancy intentions. We also asked their opinions on three distinct pregnancy intention screening and reproductive health needs assessment questions. Data analysis involved an iterative process of excerpt coding and interpretive analysis to identify key themes.

RESULTS: We conducted four FGs and 18 IDIs with a total of 39 women. Participants were receptive to the availability of RH services in primary care and the benefits to streamlining this care, provided clinicians approach these services in a manner that respects patient autonomy and reproductive desires. They discussed a lack of preconception care counseling and concerns about primary care providers' training and/or comfort with $\mathrm{RH}$, as well as time spent with patients. Participants had the most positive response to the proposed question "Can I help you with any reproductive health services today, such as birth control or planning for a healthy pregnancy?" based on its open-endedness, inclusiveness, and promotion of reproductive autonomy.

CONCLUSIONS: The findings of this study support the continued expansion of RH services in primary care settings. Future research should test the preferred RH service needs question to understand how it may affect service delivery, patient satisfaction, reproductive autonomy, as well as unmet contraceptive need and indicators of maternal and child health.

(Fam Med. 2020;52(2):112-9.)

doi: 10.22454/FamMed.2020.492002

$\mathbf{R}$ eproductive health $(\mathrm{RH})$ service provision in primary care has numerous potential patient benefits, including addressing contraceptive need and improving pregnancy outcomes through maternal health behaviors such as taking folic acid and limiting alcohol and tobacco. ${ }^{1}$ Given the recent threats to Title X funding and the August 2019 federal appeals court decision to uphold the "domestic gag rule,"2-4 implementation of $\mathrm{RH}$ services in the primary care setting is increasingly important to help ensure patient access to this care. Protocols to expand $\mathrm{RH}$ services, such as contraceptive and preconception counseling and provision, are increasingly being adopted by primary care providers. ${ }^{5,6}$ Such initiatives have involved use of reproductive life planning tools and/ or screening questions to assess patients' pregnancy intentions..$^{1,7} \mathrm{In}$ the United States these efforts have been considered best practices by the Centers for Disease Control and Prevention, Office of Population Affairs, and others. ${ }^{8-10}$

Since many individuals do not feel they can or should plan if and when to have children, ${ }^{11-15}$ pregnancy intention screening questions or planning tools in clinical encounters may not be as constructive as intended. ${ }^{15,16}$ Indeed, a systematic review of the effect of such screening on health outcomes found inconclusive evidence of its impact on contraceptive uptake or pregnancy-related outcomes. ${ }^{17}$ Additionally, if primary care clinical protocols or institutional systems do not support provision of the full range of contraceptives, there is a risk patients will feel coerced to use certain methods, particularly long-acting reversible contraceptives (LARC), which are promoted based on their effectiveness. ${ }^{18,19}$ The United States has a long history of

From the City University of New York (CUNY) School of Public Health (Drs Manze, Romero, Roberts, and Jones, and Ms Sumberg); and Dalla Lana School of Public Health, University of Toronto, Ontario, Canada (Ms Gagnon). 
violating reproductive rights, particularly for women of color, the poor, and those with intellectual disabilities. ${ }^{20-24}$ Thus, patient input into the design, implementation, and evaluation of clinical care, such as including pregnancy intention screening and $\mathrm{RH}$ services in primary care, is particularly important. ${ }^{19}$

We conducted complementary survey-based studies exploring attitudes regarding continued integration of $\mathrm{RH}$ services in primary care settings, and found both patients and providers to be receptive ${ }^{25,26}$; however, a deeper understanding of how patients prefer to receive such services is needed. This understanding would facilitate a patient-centered approach to providing $\mathrm{RH}$ services in primary care practices. Inclusion of patient perspectives when changing clinical practices can support their successful implementation and improve pregnancy and health outcomes. ${ }^{27,28}$ Thus, we sought to explore if and how women of reproductive age may want a primary care provider (PCP) to discuss pregnancy intentions and reproductive health needs with them. We also assessed participants' thoughts about receiving $\mathrm{RH}$ services in primary care settings.

\section{Methods}

\section{Study Design and Recruitment}

We employed a purposeful stratified sampling approach to recruit women to participate in focus groups (FGs) and in-depth interviews (IDIs) in New York City (NYC) and upstate New York (NYS), respectively. We used a community-based recruitment strategy, enlisting participants through flyers posted in public spaces and in-person outreach in communal spaces, such as libraries, community centers, and local stores. Inclusion criteria were: (1) self-identified as female (herein referred to as "women"), (2) age 21-40 years, and (3) living in the recruitment area. The FGs took place in 2016 and 2017; IDIs were conducted in 2018.

We stratified sampling by residential area (urban [NYC] vs suburban/rural [NYS]), age (21-30 years vs $31-40$ years, for the FGs), and neighborhood income (above vs below median county income) as these characteristics have been shown to be associated with RH-related attitudes and behaviors, and we wanted to ensure a wide range of perspectives were included. ${ }^{29-33}$ We collected data to the point of saturation across the FG and IDI samples but not within each subgroup, so we do not present stratified results. To reach a diverse group of women, we conducted four FGs among women of diverse racial/ethnic and educational backgrounds in NYC; two in a neighborhood with a median income above (Brooklyn Heights) and two below the city's median income (East Harlem). For each neighborhood, one FG included the younger age group of women and one FG included the older age group. Due to difficulties with FG recruitment in the suburban/rural locations, and as participants may be willing to share different kinds of information related to $\mathrm{RH}$ in a more intimate setting, ${ }^{34,35}$ we conducted IDIs $(n=18)$ rather than FGs with women aged 2140 years in two neighborhoods in a suburban/rural county in New York state (one above and one below the median county income: East Fishkill and Beacon, NY, respectively). Focus groups lasted about 2 hours and IDIs about 1 hour. Participants also completed brief surveys on sociodemographic characteristics including race/ethnicity, health insurance, number of children, contraceptive use, and desire for pregnancy.

The semistructured interview guides for FGs and IDIs posed questions in the same domains: pregnancy desires, $\mathrm{RH}$ care experiences, overall preferences for being asked about their pregnancy intentions and $\mathrm{RH}$ service needs, and if/how RH services should be offered by a provider in primary care settings. We specifically asked participants' opinions of three different pregnancy intention screening and $\mathrm{RH}$ needs assessment questions (Table 1). ${ }^{1,25,26,36,37}$ The Institutional Review Board at the City University of New York approved this study (\#2015-0988). All participants provided informed consent and received $\$ 25$ for their time.

\section{Analysis}

Qualitative data analysis of the transcripts followed an iterative process of code and thematic development. ${ }^{38-40}$ Three analysts conducted the initial coding; one reviewed the FG transcripts while two analyzed the IDI data. A fourth coder reviewed and edited the initial code structures. The lead author and fourth coder reconciled coding issues through discussion and review of specific cases. Analysis started with line-by-line descriptive coding and moved into focused and axial coding of salient excerpts, in order to identify emerging themes..$^{38}$ Concurrent memoing facilitated interpretative analysis. ${ }^{40}$ All data were analyzed

Table 1: Question Options for Pregnancy Intention/ Reproductive Health Service Needs Screening

\begin{tabular}{|l|l|}
\hline \multicolumn{1}{|c|}{ Question } & \multicolumn{1}{c|}{ Question Origin } \\
\hline $\begin{array}{l}\text { Would you like to become pregnant in } \\
\text { the next year? }\end{array}$ & One Key Question ${ }^{1}$ \\
\hline $\begin{array}{l}\text { Many of my patients are thinking } \\
\text { about either getting pregnant or } \\
\text { preventing a pregnancy. Where are you } \\
\text { on this issue right now? }\end{array}$ & Born out of a key informant meeting ${ }^{36}$ \\
\hline $\begin{array}{l}\text { Can I help you with any reproductive } \\
\text { health services today, such as birth } \\
\text { control or planning for a healthy } \\
\text { pregnancy?* }\end{array}$ & $\begin{array}{l}\text { Tested at a federally qualified health } \\
\text { center; most preferred by providers } \\
\text { and patients in survey studies } \\
\text { described elsewhere }\end{array}$ \\
\hline
\end{tabular}

*In-depth interviews only; based on findings from complementary studies available after FGs conducted. 
using the same final code structure in Dedoose software (v. 8.1.8). We present combined results, including descriptive statistics of participant characteristics.

\section{Results}

We collected data from 21 participants in four FGs, and from 18 participants in IDIs, for a total of 39 women in NYS (Table 2). First, we present findings from this study's primary aim of exploring women's perspectives on the integration of reproductive health services in primary care. There were three overarching themes related to participants' experiences, perceived benefits and concerns, and suggestions for RH service delivery: (1) insufficient preconception care counseling; (2) measured response to $\mathrm{RH}$ in primary care, with two subthemes: streamlined access and concerns of provider and system capabilities; and (3) nature of patient engagement. We then described participants' perspectives on the three pregnancy intention and $\mathrm{RH}$ needs screening questions. In the course of gathering data, related issues emerged regarding the political climate; thus, lastly we present noteworthy perceptions of the possible impact of current and impending legislation on participants' $\mathrm{RH}$-related decision-making. The themes and perspectives identified did not differ by data collection modality.

\section{Perspectives on Reproductive Health in Primary Care}

Insufficient Preconception Care Counseling. Participant experiences with $\mathrm{RH}$ care were largely lacking preconception care counseling. For those who did receive some form of preconception counseling, many felt that their providers had inappropriately assumed future pregnancy intention. Although 38\% of participants had children and many received $\mathrm{RH}$ care from a variety of sources (PCPs, gynecologists, midwives, school clinics), most women had not had in-depth or satisfactory discussions with their provider about preconception care. Participants noted that these discussions may have not occurred because they were young or not currently planning a pregnancy. One woman expressed her dissatisfaction with not ever being asked about planning for a healthy pregnancy:

I have so many questions about one day being able to get pregnant and like how what kind of measures I should take when I'm trying?... [but] I've never had a doctor like actually talk about, in the futureI don't even think I've really had a discussion about kids.

-IDI, upper income NYS neighborhood, age 21-30 years

Participants who had been pregnant noted that discussions about a

Table 2: Sample Sociodemographic Characteristics ( $N=39)$

\begin{tabular}{|c|c|c|c|}
\hline Variable & $\begin{array}{c}\text { Total, } \mathbf{N}=39 \\
\text { n (\%) }\end{array}$ & $\begin{array}{c}\text { Focus Groups, } \\
\text { n=21 (54) } \\
n(\%)\end{array}$ & $\begin{array}{c}\text { In-depth Interviews, } \\
\text { n=18 (46) } \\
\text { n (\%) }\end{array}$ \\
\hline \multicolumn{4}{|l|}{ Race* } \\
\hline White & $25(64)$ & $10(48)$ & $15(83)$ \\
\hline Black/African American & $9(23)$ & $7(33)$ & $2(11)$ \\
\hline Other & $3(8)$ & $1(5)$ & $2(11)$ \\
\hline Asian & $2(5)$ & $2(10)$ & $0(0)$ \\
\hline American Indian/Alaska Native & $2(5)$ & $2(10)$ & $0(0)$ \\
\hline Hispanic or Latina & $3(8)$ & $2(10)$ & $1(6)$ \\
\hline \multicolumn{4}{|c|}{ Health insurance } \\
\hline Private & $27(69)$ & $11(52)$ & $16(89)$ \\
\hline Public & $10(26)$ & $8(38)$ & $2(11)$ \\
\hline None & $2(5)$ & $2(10)$ & $0(0)$ \\
\hline \multicolumn{4}{|l|}{ Education } \\
\hline High school or less & $1(3)$ & $1(5)$ & $0(0)$ \\
\hline 2-year diploma/some college & $15(38)$ & $9(43)$ & $6(33)$ \\
\hline Bachelor's degree & $9(23)$ & $3(14)$ & $6(33)$ \\
\hline Some graduate school and above & $14(36)$ & $8(38)$ & $6(33)$ \\
\hline \multicolumn{4}{|l|}{ Relationship Status* } \\
\hline Married/Committed relationship & $19(49)$ & $9(43)$ & $10(56)$ \\
\hline Single/open relationship & $18(46)$ & $11(52)$ & $7(39)$ \\
\hline Divorced/separated/widowed & $3(8)$ & $1(5)$ & $2(11)$ \\
\hline
\end{tabular}


Table 2: Continued

\begin{tabular}{|c|c|c|c|}
\hline Variable & $\begin{array}{c}\text { Total, N=39 } \\
\text { n (\%) }\end{array}$ & $\begin{array}{c}\text { Focus Groups, } \\
\text { n=21 (54) } \\
n(\%)\end{array}$ & $\begin{array}{c}\text { In-depth Interviews, } \\
\text { n=18 (46) } \\
\text { n (\%) }\end{array}$ \\
\hline \multicolumn{4}{|c|}{ Number of Biological Children } \\
\hline 0 & $24(62)$ & $13(62)$ & $11(61)$ \\
\hline 1 & $5(13)$ & $2(10)$ & $3(17)$ \\
\hline 2 & $6(15)$ & $4(19)$ & $2(11)$ \\
\hline 3 or more & $4(10)$ & $2(10)$ & $2(11)$ \\
\hline \multicolumn{4}{|c|}{ Number of Desired Children } \\
\hline 0 & $6(15)$ & $2(10)$ & $4(22)$ \\
\hline 1 & $5(13)$ & $1(5)$ & $4(22)$ \\
\hline 2 & $13(33)$ & $7(33)$ & $6(33)$ \\
\hline 3 or more & $13(33)$ & $9(43)$ & $4(22)$ \\
\hline Don't know & $1(3)$ & $1(5)$ & $0(0)$ \\
\hline \multicolumn{4}{|c|}{ Contraception (Ever Used) * } \\
\hline Birth control pills & $33(85)$ & $17(81)$ & $16(89)$ \\
\hline Condoms & $33(85)$ & $19(90)$ & $14(78)$ \\
\hline Withdrawal & $24(62)$ & $15(71)$ & $9(50)$ \\
\hline None & $10(26)$ & $3(14)$ & $7(39)$ \\
\hline IUD & $8(21)$ & $4(19)$ & $4(22)$ \\
\hline Injectables & $8(21)$ & $4(19)$ & $4(22)$ \\
\hline Vaginal ring & $7(18)$ & $4(19)$ & $3(17)$ \\
\hline Rhythm method & $4(10)$ & $1(5)$ & $3(17)$ \\
\hline Sterilization & $3(8)$ & $2(10)$ & $1(6)$ \\
\hline Patch & $3(8)$ & $1(5)$ & $2(11)$ \\
\hline Hormonal implant & $2(5)$ & $2(10)$ & $0(0)$ \\
\hline Partner vasectomy & $1(3)$ & $0(0)$ & $1(6)$ \\
\hline Sponge & $1(3)$ & $0(0)$ & $1(6)$ \\
\hline \multicolumn{4}{|c|}{ Would Like to Be Pregnant in Next Year } \\
\hline No, but sometime in the future & $20(53)$ & $11(52)$ & $9(50)$ \\
\hline Never & $13(34)$ & $5(24)$ & $8(44)$ \\
\hline Don't know/Not sure & $4(10)$ & $3(14)$ & $1(6)$ \\
\hline Yes & $1(3)$ & $1(5)$ & $0(0)$ \\
\hline
\end{tabular}

* Items are "select all that apply"; percentages may sum above 100.

healthy pregnancy only took place after they were already pregnant, during prenatal visits.

While reporting minimal discussions of preconception care, women also recounted negative experiences when doctors had assumed they would want a pregnancy in the future. One young woman described how such an encounter led to her changing providers:
I switched to a nurse practitioner because the doctor I was originally seeing kept trying to steer most of our conversations-whether they were health-related or not to say 'you don't want children now, but you're going to probably change your mind, so you should take steps towards that.' And that was particularly offensive....My nurse practitioner is like 'I don't care whether or not you have kids. I just care that you're healthy every time you come to see me.

-FG, upper income NYC neighbor-

hood, age 21-30 years

Measured Response to RH in Primary Care. Participants had a measured response to the idea of receiving $\mathrm{RH}$ services in primary care settings, noting both (1) the benefits of having streamlined access to $\mathrm{RH}$ care, with (2) concerns about system 
and provider capabilities. Participants generally supported $\mathrm{RH}$ services being discussed and offered in primary care settings; their main concerns were related to (3) the nature of patient engagement in such conversations.

(1) Streamlined Access to RH Care. Participants felt the expansion of $\mathrm{RH}$ in primary care could create more opportunities to discuss their reproductive health in an efficient way while demonstrating that PCPs care for their patients more holistically. For example, one participant, who expressed desire for a family in the future, responded positively to the suggestion of being offered reproductive health services by a primary care provider:

...absolutely sure. And I probably don't need to go to a specialist for just routine stuff like birth control." -IDI, lower income NYS neighborhood, age 21-30 years

Participants also spoke about increased access to RH for young people, as well as for themselves:

Because my daughter is fifteen.... I send her to church for morality, but...I need the doctor to tell her every single workable door that she can use to work in this whole sexual scientific world. How to be able to go to the doctor without me knowing in order to discuss whether or not she is pregnant. What type of different contraceptives to use. How to protect herself from STDs.... I need him or her to prepare her for that world.

-FG, upper income NYC neighbor-

hood, age 31-40 years

(2) Concerns About Provider and System Capabilities. Participants had minimal concerns about discussing pregnancy with their PCP. However, they did express uncertainty about providers having sufficient time for these discussions in the clinical encounter if providing both primary care and $\mathrm{RH}$ care, and they wondered whether primary care providers were sufficiently trained to provide $\mathrm{RH}$ care. One participant expressed that sentiment:

I mean I would take whatever advice he or she $[\mathrm{PCP}]$ gave me but I think I would probably consult with the specialist the OB/GYN...Like you didn't actually specialize in that area so I'll take what you say as a physician that I should be taking these kind of vitamins or whatever the case may be, but I would still follow-up with a specialist.

$-F G$, low income NYC neighborhood, age 31-40 years

Thus, the realities of limited time in the clinical encounter and the nature of specialty training that providers had gave some respondents pause when thinking about receiving RH care from PCPs.

(3) Nature of Patient Engagement. Participants emphasized the significance of the nature of patient engagement, noting repeatedly that their relationship and comfort level with their provider and how the provider approached issues of pregnancy were of primary importance. One woman noted the importance of the provider's approach and the wording used to query patients about pregnancy:

The more the providers can do to really focus on the patient who is in front of them, the better they are going to serve that person... some of my most traumatic experiences have happened with a medical provider who just doesn't really see what's going on with me.... But thinking about wording like that can make a huge difference. -IDI, lower income NYS neighborhood, age 31-40 years

Many felt a female physician would be preferable for having these discussions, but overall how they were asked about pregnancy intentions and why the provider was asking were of key importance to women in this study. They suggested that providers first ask if patients want to discuss reproductive health services, instead of automatically initiating the conversation. Participants also asked that providers listen, follow the patient's lead, and provide nonjudgmental input. One participant expressed this sentiment:

...one of the things that I look for in any medical provider is that I appreciate someone who is going to be nonjudgmental and also give me all options, not just options that they personally back ...one of the reasons I love my OB-GYN is I can go in and see her with a list of scary things that I read on the internet and she doesn't look at me like I'm crazy.... She validates me and listens to me and gives me her medical opinion. That's the biggest thing for me. I don't want a doctor that's going to push me into something. -IDI, lower income NYS neighborhood, age 31-40 years

Ultimately, participants hoped that PCPs would first determine if patients wanted to engage in a conversation and provide information in response to patients' questions and comments rather than simply asking a question about pregnancy intentions. If PCPs were to offer $\mathrm{RH}$ counseling and services, women would want more discussion on the potential challenges they could face getting pregnant, even if they were not currently ready to have children. Additionally, participants wanted providers to discuss a comprehensive range of sexual and reproductive health services including contraception, prevention and management of sexually transmitted infections (STIs), preconception care, menstruation, and menopause. 
Perspectives on Pregnancy

Intention Screening and

Reproductive Health Needs

Assessment Questions

We presented participants with three versions of pregnancy intention screening and $\mathrm{RH}$ needs assessment questions to gain feedback on question wording and preferred approach to $\mathrm{RH}$ discussions and delivery of services in the clinical encounter. First we presented the One Key Question "Would you like to become pregnant in the next year?"1 Participants felt neutral about this question, reporting it was a "fine" way to approach asking about pregnancy. They felt it would be best suited for new patients, since providers should already know their current patients' intentions (or if they were taking birth control). Once presented with other question options, though, this question was viewed less favorably. Some voiced concerns about this phrasing and approach, including one participant who noted:

[Providers] never know emotionally what you are going through or where your relationship is or [about] your finances or your schooling...to phrase it exactly like that, is entirely random and inappropriate, I think.

-FG, upper income NYC neighborhood, age 31-40 years

We presented another version of a pregnancy intention screening question generated from a key informant planning meeting, which was "Many of my patients are thinking about either getting pregnant or preventing a pregnancy. Where are you on this issue right now?"36 Participants felt this question was less abrupt than the One Key Question, and that it opened up the conversation to both preventing pregnancy and becoming pregnant. The comparison to other patients, however, was viewed as offensive and inappropriate. Participants noted that the provider's focus should be on the patient receiving care and not others:
I don't like that [question]...It feels weird when my doctor talks to me about other patients...I don't like the way that question sets up, it makes me feel like I'm part of some survey for them.

-IDI, lower income NYS neighborhood, age 31-40 years

Some also felt it was "abrasive" and "wordy." This question elicited stronger negative feedback than the One Key Question because of its allusion to other patients.

For the in-depth interviews (only conducted in the suburban/rural regions), we had the opportunity to present a third version of a question: "Can I help you with any reproductive health services today, such as birth control or planning for a healthy pregnancy?"25,26,37 There was an overwhelmingly positive response to this question; participants felt that the question demonstrated that providers cared about patients, promoted their reproductive autonomy, did not make them feel pressured, and was comfortable.

I feel like regardless of what you say, there's no wrong answer. The doctor's willing to answer questions regardless, like he's ready." -IDI, lower income NYS neighborhood, age 31-40 years

They also felt that the question was a conversation starter that could initiate discussions not only of pregnancy, but also of STIs. Participants appreciated that this question could include female patients who had sex with people other than cisgender males.

[This question] makes the most sense because it means that there are many different types of services that you can discuss with your doctor... and it's kind of up to you to gear that conversation. It's not asking yes or no answers, and it is not comparing you to women who want to become pregnant-who are nothing like you or vice versa.
-IDI, lower income NYS neighbor-

hood, age 21-30 years

\section{Political Climate and $R H$}

Services

Of note, participants also spoke about how the political climate affected their contraceptive behavior (although not directly in relation to $\mathrm{RH}$ services being offered in primary care). While discussing the issues she weighs when deciding on contraception, one woman noted:

\section{...because right now a lot of things are changing. They are trying to shut down Planned Parenthood and abortions and rights and all this stuff is becoming political and reli- gious. I just think... I look at it like a blessing that I am able to have this opportunity in this country to be able to have these resources. -FG, low income NYC neighbor- hood, age 21-30 years}

There were concerns of the age limit being lowered for being on a parent's insurance, Planned Parenthood being defunded, and increases in abortion restrictions. Another participant expressed her fear of losing access to contraception as the impetus for getting an IUD:

Definitely one of the biggest things is that I knew that I was entering a serious relationship and I wanted to make sure that, like the extra safety and with the Trump administration, I was concerned that my health insurance would be compromised so I wanted to get something that I knew was going to be steady for three years in case there was anything to happen where it became that my birth control became unattainable.

-IDI, upper income NYS neighbor-

hood, age 21-30 years

\section{Discussion}

Our findings from this New Yorkbased sample support continued inclusion of reproductive health services in primary care. Best practices 
for primary care providers should consider that patients would like to understand why they are being asked about RH. Similar to a smaller qualitative study of pregnant women in Nebraska, ${ }^{41}$ participants in our study wanted providers to avoid making assumptions about their current or future reproductive desires. They would like for providers to first ask and be given permission to engage in a conversation about sexual and reproductive health, a technique often used in motivational interviewing. ${ }^{42}$ Those who teach family medicine can incorporate this type of dialogue into clinical training.

Participants desired adequate time to discuss myriad reproductive health needs, beyond the narrow focus of avoiding or planning for a pregnancy. As such, training should prepare providers to offer a range of services, including STI testing and other sexual health services, comprehensive contraception options, preconception care, and counseling on infertility.

Common among participants across the age and neighborhood income spectrum was the importance of how the screening question about pregnancy or RH services is worded. Interview participants' positive feedback on the question "Can I help you with any reproductive health services today, such as birth control or planning for a healthy pregnancy?" reflects their preference for being offered services without needing to have a "reproductive life plan" or intentions at that time. Moreover, it is consistent with results from other survey research of patients and providers, in which they ranked this question as their most preferred. ${ }^{25,26}$ The broad appeal of this question held true in interviews across neighborhoods in a suburban/rural county of New York. Thus, clinical education programs should consider training clinicians to administer a $\mathrm{RH}$ needs assessment question, as opposed to one of pregnancy intention.

Given the $\mathrm{RH}$ focus of the FGs and IDIs, it is not surprising that some discussion veered into the current conservative political climate. As such, both concern for possible legislative restriction of such services as well as appreciation for those that were currently available were expressed. Most mentions of the fear of reduced $\mathrm{RH}$ services were among FGs and IDIs conducted after President Trump took office in January 2017. These findings demonstrate the importance of considering how the current political climate may affect women's perceptions of $\mathrm{RH}$ service availability and their sexual and contraceptive behaviors.

These findings should be interpreted within the study limitations. Our sample includes those who selfidentified as female and live in New York, and thus may not be transferable to other populations. Although the FG and IDI interview guides were similar, the distinct modes of data collection may have generated different data. Given that FGs were conducted with urban participants and IDIs among suburban/ rural women, it is difficult to determine if any differences are due to geographic region or data collection mode. However, we did not find substantive thematic differences between FGs and IDIs. The most wellreceived screening question was only asked in the IDIs ( $\mathrm{n}=18$ suburban/ rural participants); thus, findings may have differed if the question was available when we conducted the FGs. However, separate survey research findings in support of this question phrasing provide us with greater confidence in the IDI findings. ${ }^{25,26}$ The order in which we presented questions may have affected participants' feedback; however, some individuals' inclination to use earlier examples as a referent or standard against which other options are compared may have been balanced with the opposite tendency to be more favorable toward newer options. ${ }^{43}$ The strengths of this study include both recruitment of a diverse group of women of various ages, socioeconomic statuses, and geographic locations, as well as its focus on such a timely and important topic in primary care.

Future research should test the $\mathrm{RH}$ question participants' preferred with patients across genders, to understand how it may affect service delivery, patient satisfaction, and reproductive autonomy, as well as the more ostensibly medical outcomes of unmet contraceptive need and indicators of maternal and child health. The findings of this study support the continued expansion of $\mathrm{RH}$ services in primary care settings and identified issues for deeper consideration as practitioners proceed with this integration. Specific concerns, suggestions, and preferences for how to approach patients, voiced by the study participants, can inform continued development of patient-centered $\mathrm{RH}$ services in primary care and aid clinical educators on specific aspects of primary care clinical training. Ideally, this might result in both increased reproductive autonomy for patients as well as delivery of expanded and improved sexual and reproductive health care.

ACKNOWLEDGMENTS: The authors thank Anne McGroarty, Courtney Takats, Jennifer Leimert, and Etta Bernard for their assistance with this study. They thank the members of the CUNY Faculty Fellowship Publication Program for their feedback on this manuscript.

FINANCIAL SUPPORT: This study was supported by funding from PSC-CUNY \#68437-00 46 (PI: Manze, M) and Hunter College Presidential Fund (Principal Investigators: Jones $\mathrm{H}$, Romero, D).

PRESENTATIONS: Preliminary results were presented at the Annual Public Health Association meeting on November 14, 2018 in San Diego, California.

CORRESPONDING AUTHOR: Address correspondence to Dr Meredith G. Manze, 55 W 125th St, New York, NY 10027. 646-364-0251. Meredith.manze@sph.cuny.edu.

\section{References}

1. Bellanca HK, Hunter MS. ONE KEY QUESTION: preventive reproductive health is part of high quality primary care. Contraception. 2013;88(1):3-6

2. Hasstedt K. Title X under Attack-Our comprehensive guide. Guttmacher Institute Policy Analysis. March 2019. https://www.guttmacher. org/article/2019/03/title-x-under-attack-ourcomprehensive-guide. Accessed August 21, 2019 . 
3. Hasstedt K. Shoring up reproductive autonomy: Title X's foundational role. Guttmacher Institute. July 17, 2019; Volume 22. https:// www.guttmacher.org/gpr/2019/07/shoring-reproductive-autonomy-title-xs-foundational-role. Accessed August 21, 2019.

4. US Department of Health \& Human Services. Fact sheet: Final Title X rule detailing family planning grant program. https://www.hhs.gov/ about/news/2019/02/22/fact-sheet-final-title-xrule-detailing-family-planning-grant-program html. Updated February 22, 2019. Accessed August 21, 2019.

5. Wood S, Beeson T, Bruen B, et al. Scope of family planning services available in Federally Qualified Health Centers. Contraception. 2014;89(2):85-90.

6. Bello JK, Rao G, Stulberg DB. Trends in contraceptive and preconception care in United States ambulatory practices. Fam Med. 2015;47(4):264-271.

7. Allen D, Hunter MS, Wood S, Beeson T. One key question $(\mathrm{R})$ : first things first in reproductive health. Matern Child Health J. 2017;21(3):387-392.

8. Office of Population Affairs. Preconception health \& reproductive life plan. January 28, 2019. https://www.hhs.gov/opa/title-x-familyplanning/preventive-services/preconceptionhealth-and-reproductive-life-plan/index.html. Accessed August 21, 2019.

9. Johnson K, Posner SF, Biermann J, Cordero JF; CDC/ATSDR Preconception Care Work Group; Select Panel on Preconception Care. Recommendations to improve preconception health and health care-United States. A report of the CDC/ATSDR preconception care work group and the select panel on preconception care. MMWR Recomm Rep. 2006;55(RR-6):1-23.

10. Dunlop AL, Jack B, Frey K. National recommendations for preconception care: the essential role of the family physician. J Am Board Fam Med. 2007;20(1):81-84

11. Manze MG, Watnick D, Romero D. A qualitative assessment of perspectives on getting pregnant: the Social Position and Family Formation study. Reprod Health. 2019;16(1):135.

12. Borrero S, Nikolajski C, Steinberg JR, et al. "It just happens": a qualitative study exploring low-income women's perspectives on pregnancy intention and planning. Contraception. 2015;91(2):150-156.

13. Jones RK, Frohwirth LF, Blades NM. "If I know I am on the pill and I get pregnant, it's an act of God": women's views on fatalism, agency and pregnancy. Contraception. 2016;93(6):551-555.

14. Barrett G, Wellings $\mathrm{K}$. What is a 'planned' pregnancy? Empirical data from a British study. Soc Sci Med. 2002;55(4):545-557.

15. Aiken AR, Borrero S, Callegari LS, Dehlendorf C. Rethinking the pregnancy planning paradigm: unintended conceptions or unrepresentative concepts? Perspect Sex Reprod Health. 2016;48(3):147-151.

16. Callegari LS, Aiken AR, Dehlendorf C, Cason P, Borrero S. Addressing potential pitfalls of reproductive life planning with patientcentered counseling. Am J Obstet Gynecol. 2017;216(2):129-134
17. Burgess CK, Henning PA, Norman WV, Manze MG, Jones HE. A systematic review of the effect of reproductive intention screening in primary care settings on reproductive health outcomes. Fam Pract. 2018;35(2):122-131.

18. Higgins JA. Celebration meets caution: LARC's boons, potential busts, and the benefits of a reproductive justice approach. Contraception. 2014;89(4):237-241.

19. Gubrium AC, Mann ES, Borrero S, et al. Realizing reproductive health equity needs more than long-acting reversible contraception (LARC). Am J Public Health. 2016;106(1):18 19

20. Thorburn S, Bogart LM. African American women and family planning services: perceptions of discrimination. Women Health. 2005;42(1):23-39

21. Roberts D. Killing the black body: Race, reproduction and the meaning of liberty. New York: Vintage; 1998.

22. Novak NL, Lira N, O’Connor KE, Harlow SD, Kardia SLR, Stern AM. Disproportionate sterilization of Latinos under California's eugenic sterilization program, 1920-1945. Am J Public Health. 2018;108(5):611-613.

23. López I. Matters of Choice: Puerto Rican Women's Struggle for Reproductive Freedom. New Brunswick, NJ: Rutgers University Press; 2008.

24. Tone A. Controlling Reproduction: An American History. Lanham, MD: SR Books; 2008.

25. Manze M, Calixte C, Romero D, et al. Physician perspectives on expanding pregnancy intention screening and counseling in primary care Contraception. 2020 (in press).

26. Jones H, Calixte C, Manze M, et al. Patient care patients' preferences for reproductive health service needs assessment and service availability in New York federally qualified health centers. Contraception. 2020 (under review).

27. Montori VM, Brito JP, Murad MH. The optimal practice of evidence-based medicine incorporating patient preferences in practice guidelines. JAMA. 2013;310(23):2503-2504.

28. Krahn M, Naglie G. The next step in guideline development: incorporating patient preferences. JAMA. 2008;300(4):436-438

29. Daniels K, Abma JC. Current contraceptive status among women aged 15-49: United States, 2015-2017. National Center for Health Statistics. December 2018;Brief \#327.

30. Daugherty J, Copen C. Trends in attitudes about marriage, childbearing, and sexual behavior: United States, 2002, 2006-2010, and 2011-2013. National Health Statistics Report. March 17, 2016;Number 92.

31. Daniels K, Daugherty J, Jones J. Current contraceptive status among women aged 15-44: united States, 2011-2013. NCHS Data Brief. 2014;(173):1-8.

32. Daniels K, Martinez GM, Nugent CN. Urban and rural variation in fertility-related behavior among U.S. women, 2011-2015. National Center for Health Statistics. January 2018; NCHS Data Brief No. 297.
33. Committee on Health Care for Underserved Women. Health disparities in rural women. The American College of Obstetricians and Gynecologists. February 2014; Number 586.

34. Elam G, Fenton KA. Researching sensitive issues and ethnicity: lessons from sexual health. Ethn Health. 2003;8(1):15-27.

35. Elmir R, Schmied V, Jackson D, Wilkes L. Interviewing people about potentially sensitive topics. Nurse Res. 2011;19(1):12-16.

36. Romero D, Manze M, Roberts L, McGroarty A, Jones H. Stakeholder perspectives on reproductive health in primary care, LARC provision and reproductive justice: A qualitative study. Contraception. 2020 (under review).

37. Shah SD, Prine L, Waltermaurer E, Rubin SE. Feasibility study of family planning services screening as clinical decision support at an urban Federally Qualified Health Center network. Contraception. 2019;99(1):27-31.

38. Charmaz K. Constructing Grounded Theory: A Practical Guide Through Qualitative Analysis (Introducing Qualitative Methods Series). Thousand Oaks, CA: Sage Publications; 2006.

39. Glaser B, Strauss A. The Discovery of Grounded Theory: Strategies for Qualitative Research. Chicago, IL: Aldine Publishing Company; 1967.

40. Corbin J, Strauss A. Basics of Qualitative Research: Techniques and Procedures for Developing Grounded Theory. 3rd ed. Thousand Oaks, CA: Sage Publications, Inc; 2007:400.

41. French VA, Steinauer JE, Kimport K. What women want from their health care providers about pregnancy options counseling: A qualitative study. Womens Health Issues. 2017;27(6):715-720.

42. Sobell LC, Sobell MB. Motivational techniques and skills for health and mental health Coaching/Counseling. 2013. https://www.nova.edu/ gsc/forms/mi-techniques-skills.pdf. Accessed August 21, 2019.

43. Babbie ER. Survey Research Methods. 2nd ed. Boston, MA: Cenage Learning; 1990. 